\title{
Mathematical Model on Branch Canker Disease in Sylhet, Bangladesh
}

\author{
Rahman, S.M.S. ${ }^{1}$ Islam, M.A. ${ }^{2}$ Shahrear, P. ${ }^{3 *}$ Islam, M.S. ${ }^{4}$ \\ ${ }^{1 .}$ M.S. (Thesis), Department of Mathematics, Shahjalal University of Science and Technology, Sylhet-3114, Bangladesh \\ 2. Professor, Department of Mathematics, Shahjalal University of Science and Technology, Sylhet-3114, Bangladesh \\ 3. Associated Prof., Department of Mathematics, Shahjalal University of Science and Technology, Sylhet, Bangladesh \\ 4. Senior Scientific Officer, Plant Pathology Division, Bangladesh Tea Research Institute, Srimangal, Bangladesh
}

\begin{abstract}
Members of the Camellia genus of plants may be affected by many of the diseases, pathogens and pests that mainly affect the tea plant (Camellia sinensis). One of the most common diseases which are found in tea garden is known as Branch Canker (BC) [1]. Recent outbreaks of these diseases is not only hampering the production of tea, but also stupendously hampering our national economy. In this paper, a simple SEIR model has been used to analyze the dynamics of Branch Canker in the tea garden. The stability of the system is analyzed for the existence of the disease free equilibrium. We established that there exists a disease free equilibrium point that is locally asymptotically stable when the reproduction number $R_{o}<1$ and unstable when $R_{o}>1$. Theoretically, we analyze the BC model. Finally, we numerically tested the theoretical results in MATLAB.
\end{abstract}

Keywords: Mathematical Model, Tea disease, Stability Analysis, Reproduction Number, Epidemiology, Equilibrium, $O D E$.

\section{Introduction}

Like other living being, plants are bound to be victim of diseases, which may also come as an epidemic form creating a heavy toll of lives of plants. We are accustomed to having different kinds of drinks in our daily life. Out of all such kinds of all drinks, tea is one of the most popular drinks of the world, which are produced more than 50 countries around the world. Tea is basically produced from the tea plant. But sometimes these plants are affected by lots of diseases. Generally these diseases are caused by pathogens, a group of micro organs, which weaken the plants, kill the metabolism and block the transportation of food of host plants. The diseases gradually make the plants weak and destroy immune system leading plants to death ultimately.

Actually, the flush shoots of the tea plant are suitable to use as drink. $81.4 \%$ of total tea is produced in Asia followed by Africa and Latin America having the production of $15.5 \%$ and 2\% respectively [2]. In Bangladesh, there are 169 tea estates [3] comprising around 59.609 thousand hectares produce 63.86 million kg [3] of made tea which is $0.11 \%$ of entire GDP creating employment for almost 0.30 million people. Comparing to the other tea growing countries, the tea production per hectare in Bangladesh is relatively much low $(1,239 \mathrm{~kg} / \mathrm{ha})$ [3] if the cultivation is considered. Among other factors, disease is the key one.

Tea plants are forced to grow under monoculture conditions where diseases may attack in a sporadic or epidemic form. While it is in epidemic form, it directly hits our national economy negatively. Although majority of the diseases of tea plants are of fungal origin, more than 400 pathogens [4] are responsible for other disease like 18 algal disease and few epiphytes [5] which attack the foliage, stem and root of tea plants.

In Bangladesh, common tea diseases and their positions are stated in following table:

\begin{tabular}{|l|l|l|l|}
\hline Name of Diseases & Causal organisms & Infected parts & Status \\
\hline Branch canker & Macrophoma theicola & Stem \& Branch & Major \\
\hline Red rust & Cephaleuros parasiticus & Stem \& Branch & Major \\
\hline \multirow{2}{*}{ Charcoal stump rot } & Ustulina zonata & Stump \& Root & Major \\
\cline { 2 - 4 } & Ustulina deusta & Stump \& Root & Major \\
\hline Violet root rot & Sphaerostilbe repens & Root & Minor \\
\hline
\end{tabular}

The total crop loss in tea sector in Bangladesh causes due to some diseases, specifically, Red rust disease causes 1820\%, Gall 20-25\%, Horsehair Blight 11-13\% [6], Branch canker and Black rot cause 25-35\% loss. Red rust is a leading 
steam diseases in tea garden, which is basically caused by alga, Cephaleuros parasiticus karast [7][8] and Black rot is the most vicious leaf disease of tea caused by Corticium theae Bernard [9][10].

Root diseases are the common features of tea garden. Charcol stump rot (Ustulina destua) and Violet root rot (Spherostible repens) are two of the most common root diseases in Bangladesh. Charcol stump rot not only attacks tea but also many other plants like Albizzia odoratissima, A. Procera, Derris robusta, Tephrosia candida etc [11]. Violet root attack many plants of all ages starting from two years and is unreported on the hills.

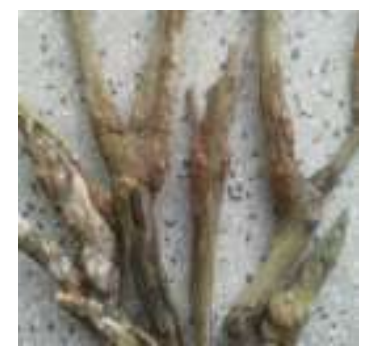

Figure: 1 Branch Canker

Due to Macrophoma theicola petch fungas, Branch Canker (Figure 1), a stem disease of tea plants is commonly seen which tolls a heavy loss in tea production in Bangladesh [1][5][12]. Around 15-25\% crop loss is recorded due to the attack of this disease.

Microclimate, the climate of a very small or restricted area that differs from the surrounding area, is significantly affected by the architectures of tree plantation since there are Tillah, Flat and Kunchi may be found in the same area. Such topographical varieties directly influence on access of solar rays, moisture, heat and air flow, thus affect plant growth and diseases development [13].

In fine, in this paper, we have tried to develop the Branch Canker model (can be named as BC model) to derive the disease -free equilibrium and the endemic and the endemic equilibrium. We have done a qualitative analysis of the model. Stability conditions for the disease-free equilibrium and the endemic equilibrium are derived as well as numerically tested the theoretical results in MATLAB.

\section{Formulation of the Branch Canker (BC) Model}

We need to formulate five classes of plants such as, susceptible class, asymptomatic infected class, symptomatic infected class, quarantine class and recovered class by using SEIR model [14-18] with a view to studying the compartmental mathematical Branch Canker model. Each group or compartment is shown in Figure 2.

$\mathrm{S}(\mathrm{t})$ represents the number of individuals which is not yet infected with the disease at time $\mathrm{t}$ or those which is susceptible to the disease. $\mathrm{E}(\mathrm{t})$ represents the number of asymptomatic infectious individuals (plants infected with disease not showing the symptoms) at time $t . \mathrm{I}(\mathrm{t})$ is the number of symptomatic infectious individual (plants infected with disease showing the symptoms) at time t. $\mathrm{Q}(\mathrm{t})$ is the number of quarantine individuals (plants which have been infected with disease but do not to spread the disease among the other susceptible) at time t.

$R(t)$ is the number of recovered individuals (plants infected though recovered are also unable to be infected further or to be contagious) at time $\mathrm{t}$. Therefore, the compartment SEIR model for BC is shown in figure 2. Symptomatic as well as asymptomatic infectious individuals are able to spread the disease to other plants, which are susceptible. The dynamics of the model for each compartment is then governed by the following set of differential equations [19]: 


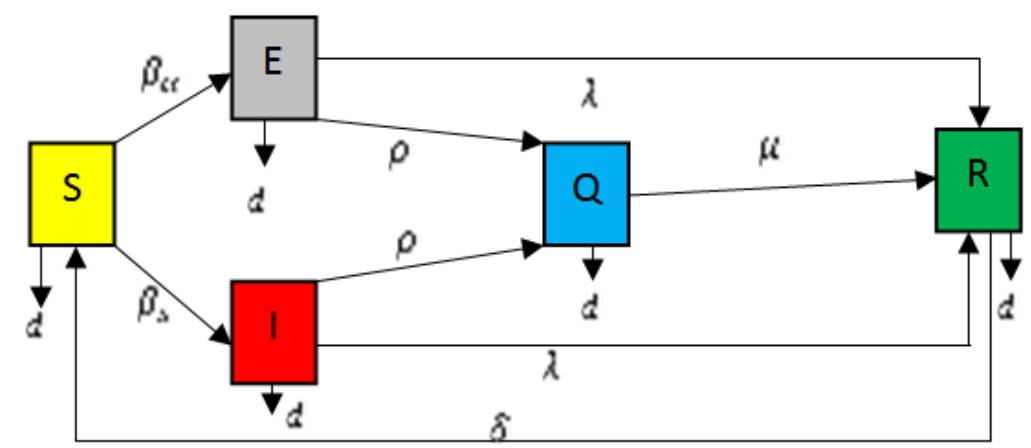

Figure 2: Branch canker disease (BC) model

$\frac{d S}{d t}=\left(+{ }_{s}\right) S I+R \quad d S$

$\frac{d E}{d t}=\beta_{\alpha} S I-(\rho+\lambda) E-d E$

$\frac{d I}{d t}=\beta_{S} S I-(\rho+\lambda) I-d I$

$$
\begin{aligned}
& \frac{d Q}{d t}=(E+I) \quad \mu Q \quad d Q \\
& \frac{d R}{d t}=\mu Q+\lambda(E+I)-\delta R-d R
\end{aligned}
$$

In the following tables, the variables and parameters used in the model are defined:

Table 1: Model Variables

\begin{tabular}{|l|l|}
\hline Variables & Description \\
\hline $\mathrm{S}(\mathrm{t})$ & Susceptible class \\
\hline $\mathrm{E}(\mathrm{t})$ & Asymptomatic infectious class \\
\hline $\mathrm{I}(\mathrm{t})$ & Symptomatic infectious class \\
\hline $\mathrm{Q}(\mathrm{t})$ & Quarantine class \\
\hline $\mathrm{R}(\mathrm{t})$ & Recovered class \\
\hline
\end{tabular}

Table 2: Model Parameters

\begin{tabular}{|l|l|}
\hline Parameters & Description \\
\hline$d$ & Birth and Death rate \\
\hline & Transmission co-efficient (asymptomatic) \\
\hline$s$ & Transmission co-efficient (symptomatic) \\
\hline & Recovery or removal rate \\
\hline & contact rate from asymptomatic infected class and symptomatic infected to quarantine class \\
\hline & Contact rate from Quarantine class to Recovered individuals class \\
\hline & Contact rate from Recovered class to Susceptible class \\
\hline
\end{tabular}

\section{Equilibrium Analysis}

Equilibrium condition states us that the left hand side (L.H.S) of the system equations of B.C. will be zeros, i.e.,

$$
\frac{d S}{d t}=0 ; \frac{d E}{d t}=0 ; \frac{d I}{d t}=0 ; \frac{d Q}{d t}=0 ; \frac{d R}{d t}=0
$$


For the B.C. model given by the systems of Equation (1) the following properties hold when plants with constant size are assumed.

The equilibrium point without infection called disease free equilibrium is given by:

$\mathrm{S}=1, \mathrm{E}=0, \mathrm{I}=0, \mathrm{Q}=0, \mathrm{R}=0$

Thus we can take the disease free equilibrium as $(1,0,0,0,0)$.

The equilibrium point with infection called endemic equilibrium is given by:

$$
\begin{aligned}
& S=\frac{\delta R}{\left(\beta_{\alpha}+\beta_{s}\right) I+d}=S^{*} \\
& E=\frac{\beta_{\alpha} S I}{\rho+\lambda+d}=E^{*} \\
& I=\frac{\beta_{s} S I}{\rho+\lambda+d}=I^{*} \\
& Q=\frac{\rho(E+I)}{\mu+d}=Q^{*} \\
& R=\frac{\mu Q+\lambda(E+I)}{\delta+d}=R^{*}
\end{aligned}
$$

\section{Model Analysis}

We need to examine the behavior of the model plant near the equilibrium solutions (the disease free and the endemic) to analyze the stability of each of the two equilibriums of the BC. We will investigate the local stability of the steady state of the disease model by the eigenvalues of the associated Jacobian matrices of the system equations [20,21]. Therefore, for the system of (1); the Jacobian matrix is:

$$
J=\left[\begin{array}{ccccc}
-\left(\beta_{\alpha}+\beta_{s}\right) I-d & 0 & -\left(\beta_{\alpha}+\beta_{s}\right) S & 0 & \delta \\
\beta_{\alpha} I & -(\rho+\lambda+d) & \beta_{\alpha} S & 0 & 0 \\
\beta_{s} I & 0 & \beta_{s} S & 0 & 0 \\
0 & \rho & \rho & -\mu & 0 \\
0 & \lambda & \lambda & \mu & -d
\end{array}\right]
$$

At the disease free equilibrium i.e. at $\mathrm{I}=0$ the Jacobian matrix would be as follows (considering the total fraction of Susceptible $S=1$ ), the Jacobian matrix becomes

$$
J^{0}=\left[\begin{array}{cccccc}
d & 0 & \left(+{ }_{s}\right) & 0 & \\
0 & (++d) & & 0 & 0 \\
0 & 0 & s & (++d) & 0 & 0 \\
0 & & & & & 0 \\
0 & & & & d
\end{array}\right]
$$

Now from equation (3) we have characteristic polynomial,

$$
(a+d)(a+d)(a+)(a+++d)\left(a{ }_{s}+++d\right)=0
$$


Hence the eigenvalues are as follows:

$$
a_{1}=d, a_{2}=d, a_{3}=\quad, a_{4}=(++d), a_{5}={ }_{s}(++d)
$$

Theorem 1: The disease free equilibrium (DFE) is stable if $R_{0}<1$.

The disease free equilibrium for the model only exists if all the eigenvalues are non-positive. This holds of,

$$
\begin{aligned}
& { }_{s}(++d)<0 \\
& <(++d) \\
& \frac{s}{+\quad+d}<1 \\
& R_{0}<1
\end{aligned}
$$

i.e. the basic reproductive number,

$$
R_{0}=\frac{s}{++d}
$$

At endemic of equilibrium, the Jacobian matrix becomes:

$J^{*}=\left[\begin{array}{ccccc}-\left(\beta_{\alpha}+\beta_{s}\right) I^{*}-d & 0 & -\left(\beta_{\alpha}+\beta_{s}\right) S^{*} & 0 & \delta \\ \beta_{\alpha} I^{*} & -(\rho+\lambda+d) & \beta_{\alpha} S^{*} & 0 & 0 \\ \beta_{s} I^{*} & 0 & \beta_{s} S^{*} & 0 & 0 \\ 0 & \rho & \rho & -\mu & 0 \\ 0 & \lambda & \lambda & \mu & -d\end{array}\right]$

$$
=\left[\begin{array}{ccccc}
\frac{S I\left(+{ }_{s}\right)}{++d} & d & 0 & \left(+{ }_{s}\right) \frac{R}{\left(+{ }_{s}\right) I+d} & 0 \\
\frac{S I}{++d} & (++d) & \frac{R}{\left(+{ }_{s}\right) I+d} & 0 \\
\frac{{ }_{s} S I}{++d} & 0 & \frac{R}{\left(+{ }_{s}\right) I+d} & 0 \\
0 & & d
\end{array}\right]
$$

The eigenvalues of $J^{*}$ could all be negative, positive, zero or any combinations of the three alternatives on the basis of various combinations of model parameters. Thus the endemic equilibrium can be stable, unstable or saddle with respect to the different values of the various model parameters pooled at a given time [22-24].

\section{Numerical Simulation and results for BC Model}

We are going to discuss the numerical simulation and findings from BC model in this section. We have solved the system for the model by using MATLAB. The baseline variables and used parameters estimated for Bangladesh are shown in the following tables. Although data we used are actually based on approximations. We found that our approximations are actually correct enough to present the model appropriately. When there is no treatment, we consider the treatment parameters as zero i.e. $\lambda=0$ and $\mu=0$.

Table 3: Values of Branch Canker Disease model parameters 


\begin{tabular}{|l|l|}
\hline Parameters & Values \\
\hline & 0.0000 \\
\hline$d$ & 0.2272 \\
\hline & 0.0000 \\
\hline & 0.1251 \\
\hline & 0.1717 \\
\hline & 0.1031 \\
\hline & 0.1258 \\
\hline
\end{tabular}

When there is no treatment, i.e. $\lambda=0$ and $\mu=0$, we have plotted the following graphs in MATLAB:

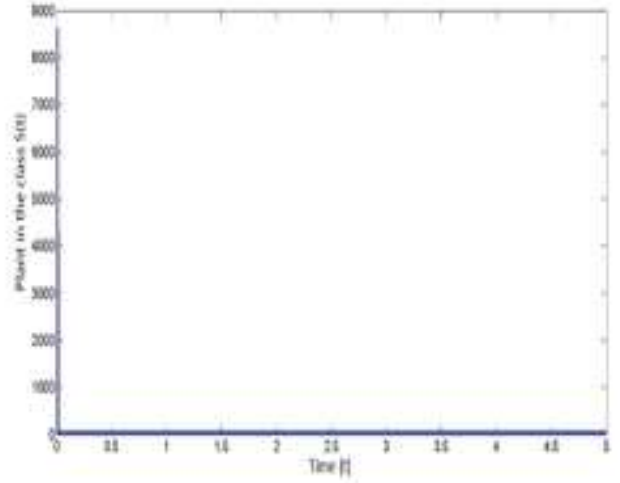

(a) Situation of the class $S(t)$

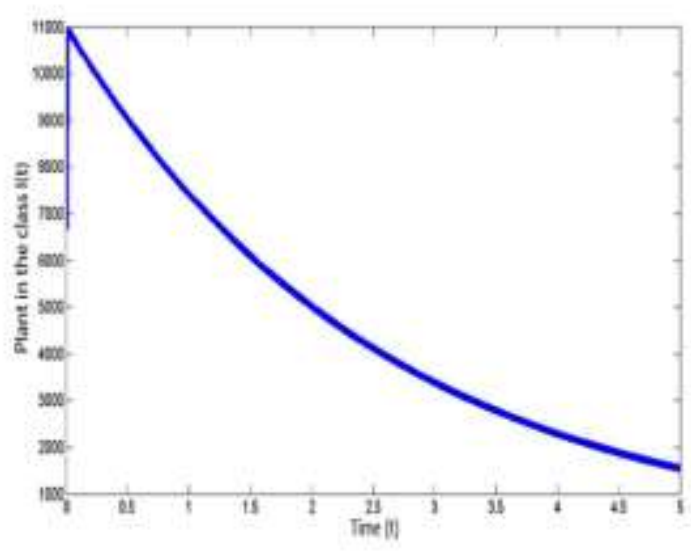

(c) Situation of the class $I(t)$

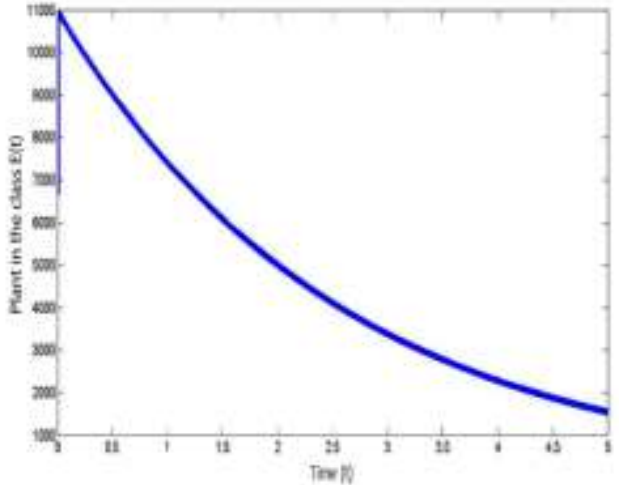

(b) Situation of the class $E(t)$

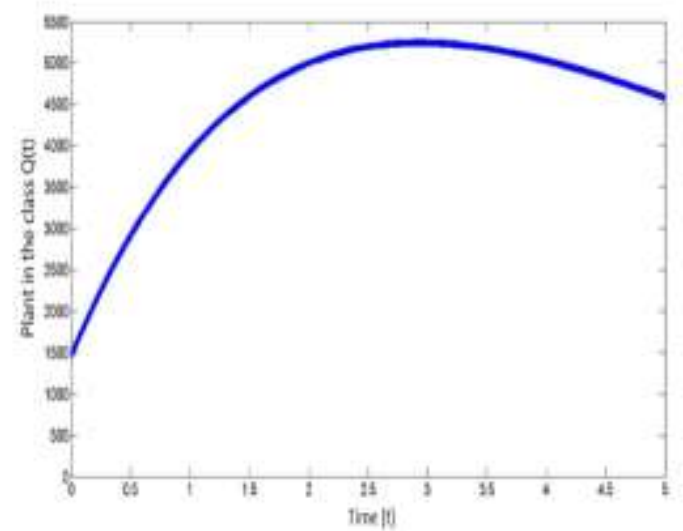

(d) Situation of the class $Q(t)$

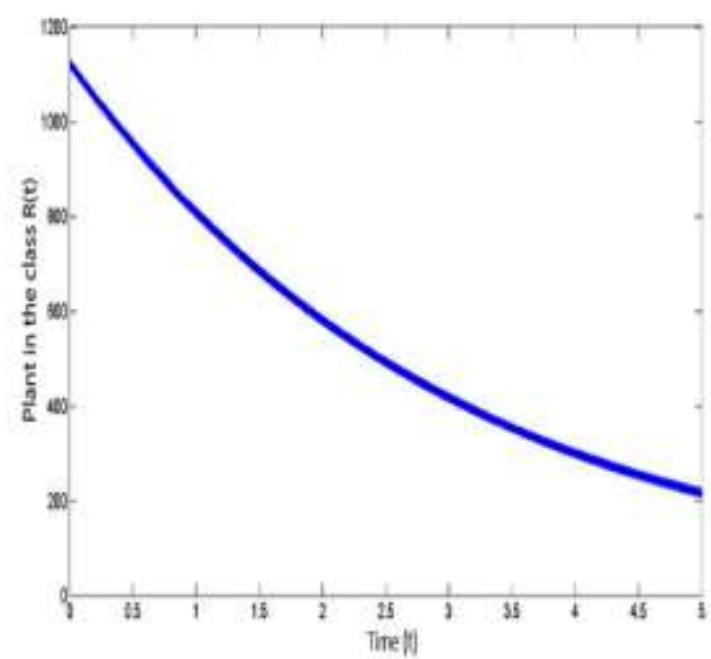




\section{(e) Situation of the class $R(t)$}

Figure 3: Situation of different plant classes with respect to time when there is no treatment

\section{Result and discussion from the figure 3}

Figure 3 depicts us that when there are no treatments i.e. $\lambda=0, \mu=0$, the curve for the recovery class $\mathbf{R}(\mathbf{t})$ becomes continuously decreasing. It means the plant in the recovery class decreases with respect to time. So for the recovery from the disease, the treatment is a must. When there are treatments, we consider the treatment parameters as $\lambda=0.1257$ and $\mu=0.3151$

Table 4: Values of Branch Canker Disease model parameters

\begin{tabular}{|l|l|}
\hline Parameters & Values \\
\hline & 0.3151 \\
\hline$d$ & 0.2272 \\
\hline & 0.1257 \\
\hline & 0.1251 \\
\hline & 0.1717 \\
\hline & 0.1031 \\
\hline$s$ & 0.1258 \\
\hline
\end{tabular}

When there are treatments i.e. when $\lambda=0.1257$ and $\mu=0.3151$, we have plotted the following graphs in MATLAB:

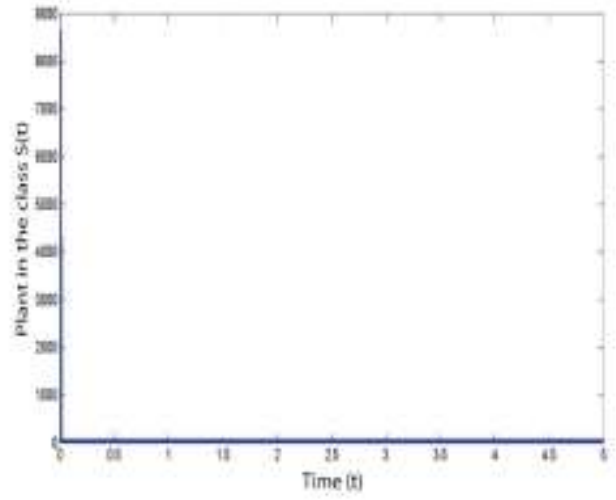

(a) Situation of the class $S(t)$

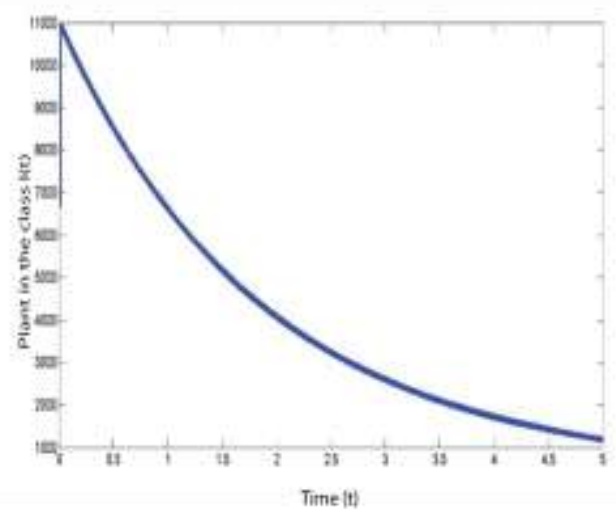

(c) Situation of the class $I(t)$

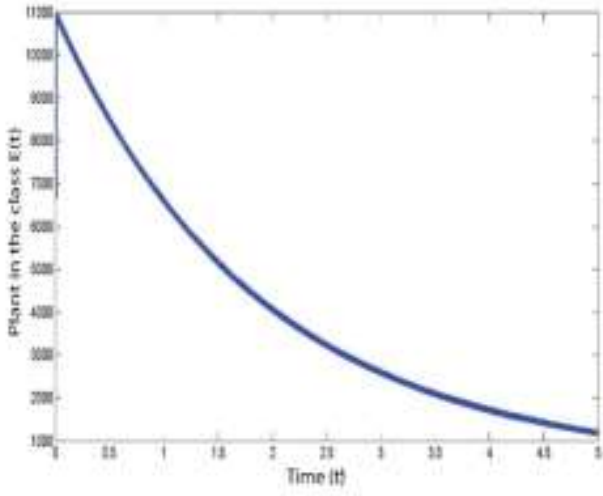

(b) Situation of the class $E(t)$

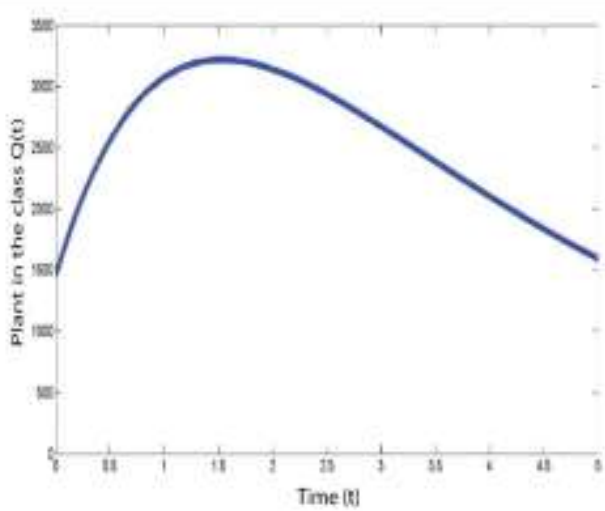

(d) Situation of the class $Q(t)$ 


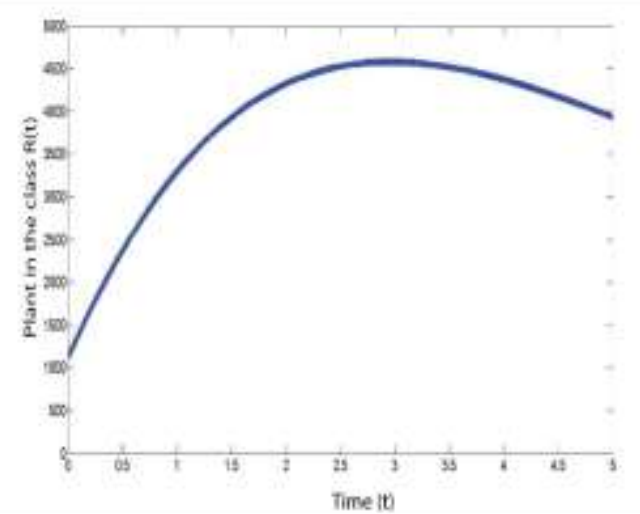

(e) Situation of the class $R(t)$

Figure 4: Situation of different plant classes with respect to time when there exist treatments

\section{Result and discussion from the figure 3}

From the figure 4, we observe that when there exist treatments, the curve for the recovery class $\mathbf{R}(\mathbf{t})$ start to increase. And it is going on till a certain period of time. Then when the treatments are done, it is starts to decrease again. Also the reduction of the plant in the $\mathbf{E}(\mathbf{t}), \mathbf{I}(\mathbf{t})$ and $\mathbf{Q}(\mathbf{t})$ classes becomes quicker when there exist treatments i.e. $\lambda=0.1257$ and $\mu=0.3151$. So, we can conclude asserting that treatments can recover the disease easily.

\section{Conclusion}

In this paper we have presented the Branch Canker model. This analysis of such model is based on SEIR model. To the best of our knowledge, for the first time we used SEIR model to investigate the dynamics of tea disease in Sylhet, Bangladesh. We have introduced a compartment that efforts on recovering disease from tea garden. The resulting model has been solved analytically. The equilibria and their stabilities have been also presented. Numerical simulations of the system have been presented to show the variations of the plant in different situations. Data that have been used for the simulations are based on the tea diseases in Sylhet, Bangladesh. We found that our approximations are actually correct enough to represent the BC model appropriately.

\section{References}

[1]. Ali, M. and Huq, M., 1993, Branch Canker (Macrophoma) In Tea. pp. 5-11.

[2]. Food and Agriculture Organization, 1999

[3]. PDU (Project Development Unit), 2015. Statistics on Bangladesh Tea Industry-2015. Bangladesh Tea Board, Srimangal, Moulvibazar. pp. 26-66.

[4]. Chen, Z.M. and Chen. X.F., 1990. The diagnosis of tea diseases and their control in Chinese. Shanghai Sci. Tech. publishers, Shanghai, China. pp. 73-88.

[5]. Sana, D. L., 1989, TEA SCIENCE. pp: 1-269.

[6]. Ali, M. and Huq, M., 2009, Horse Hair Blight of tea and its management. pp. 1-5.

[7]. Huq, M., Ali M. and Islam, M.S., 2007. Red rust disease of tea and its management. Memo. No.1. BTRI. pp. 1-8.

[8]. Sarmah, K.C., 1960. Red rust- Cephaleuros parasitiaus Karst. Disease of tea and associated crops in North-East India. Memo. No. 26. Ind. Tea Asso. pp. 44-46.

[9]. Ali, M.A., 1992. Black rot disease of tea. Pamphlet no. 14. Bangladesh Tea Res. Inst. Srimangal. pp. 5-10.

[10]. Ali, M., 1993, Black Rot disease of Tea. pp. 5-10.

[11]. Ali, M., 1993, Charcoal Stump Rot disease of tea, pp. 5-14.

[12]. Bangladesh Tea Research Institute (BTRI), Srimangal-3210, Moulvibazar.

[13]. Islam, M.S. and Ali., M., 2010. Incidence of Major Tea Diseases in Bangladesh. Bangladesh J. Agril. Res. 35 (4): $605-610$.

[14]. Daley, D.J. and Gani, J., 2005. Epidemic Modeling: An Introduction. NY: Cambridge University Press.

[15]. Hethcote, H. W., 2000. "The mathematics of infectious diseases."Society for industrial and Applied Mathematics, 42, pp. 599-653.

[16]. Weiss, H. and Tech, G. A Mathematical Introduction to population Dynamics under construction, pp. 5-137.

[17]. BjØrnstad, O., May 16, 2005. SEIR models, pp. 1-8.

[18]. Brauer, F. and Castillo-Chảvez, C. 2001. Mathematical Models in Population Biology and Epidemiology, Springer-Verlag NY, Inc, pp. 1363.

[19]. Shepley L. Ross, 2005, Differential Equations, pp. 3-757.

[20]. Anton, H. and Rorres C., 2006, Elementary Linear Algebra, pp. 1-768.

[21]. Lipschutz S., and Lipson M.L., Linear Algebra, pp. 1-402.

[22]. Roussel, M.R., September 13, 2005. Stability Analysis for ODEs, pp. 1-13.

[23]. Lungu, E. M., Kgosimore, M. and Nyabadza, F., February 2007, LECTURE NOTES: MATHEMATICAL EPIDEMIOLOGY, pp. 45-62.

[24]. Roy N., 2012, Mathematical Modeling of Hand-Foot-Mouth disease: Quarantine as a Control Measure, pp. 39. 